\title{
El miedo del estudiantado a presentar quejas en la Universidad
}

The fear of the students to complain at the University

\author{
Coordinadora de Representantes de Estudiantes \\ de Universidades Públicas \\ https://www.creup.es/
}

N.B.: Este artículo responde a una reflexión realizada por la Coordinadora sobre los planteamientos del artículo anterior en relación con las emociones del miedo.

CREUP es la Coordinadora de Representantes de Estudiantes de Universidades Públicas, formada por 33 consejos de estudiantes de universidades públicas y representante de más de 1.000.000 de estudiantes universitarios. Se trata del principal agente de representación estudiantil universitario a nivel Estatal, es la voz del estudiantado ante entidades e instituciones públicas para la construcción y mejora del Sistema Universitario.

El estudiantado debe conocer la institución de la Defensoría Universitaria y ser visualizada como un elemento útil. Es por ello que desde CREUP recomendamos la inclusión de referencias en las diferentes jornadas de bienvenida de las universidades, en las que se da información sobre la Universidad y en las que debería reflejarse qué es y para qué sirve la figura de la defensoría. Además, muchas cuentan con programas en los que estudiantes de cursos superiores guían a los de nuevo ingreso y les proporcionan información sobre los diferentes servicios de la universidad y su funcionamiento, también en estos programas se debería hacer hincapié e incluir conocimientos. Sin olvidarnos en todo momento de la necesidad de establecer alianzas con los órganos de representación estudiantil de las universidades, con el objetivo de que tengan presente a la institución. Así es como nuestros compañeros y compañeras de cada universidad podrán canalizar los problemas susceptibles de actuación por parte del defensor o defensora. Con esta alianza la canalización con el estudiantado pasa a ser más sencilla y directa.

No hay que olvidar que vivimos en la era de la digitalización y las redes sociales, la mayoría de los jóvenes acuden a ellas a la hora de buscar una institución. Por lo que proponemos la habilitación de un apartado, visible, específico en cada una de las webs de las diferentes universidades y el refuerzo de la comunicación de la institución a través de redes sociales. Lo que genera una mayor visibilidad y aumenta el conocimiento por parte del estudiantado.

Todo ello son medidas que desde la Coordinadora consideramos que deberían comenzar a aplicarse y reclamarse por parte de las defensorías universitarias. 
Entrando a la cuestión a abordar, ¿hay miedo por parte del estudiantado a presentar quejas en la universidad?

Tal y como afirma Jesús de Alba, anterior presidente de CREUP, "Sí, existe el miedo entre muchos estudiantes a hacer valer sus derechos. Lo preocupante es que el miedo paraliza, el miedo hace que las personas dejen de actuar".

Ante esta afirmación Jesús reflexiona sobre la necesidad de preservar el anonimato del estudiante, siempre que sea posible, debido a que el estudiante tiene miedo a las represalias. También afirma que es cierto que en muchas ocasiones no se puede preservar el anonimato, como la reclamación de la evaluación de un examen. A raíz de esto nos cuenta un caso que encontró como Delegado de centro de la Facultad de Derecho en la Universidad de Cádiz, en la que la docente titular de la asignatura únicamente había contemplado cinco tipos de calificaciones $(0-1,7-3,2-6,5$ y 8,3) además de un alto índice de suspensos. El estudiantado de la asignatura, con la ayuda de la Delegación, formalizó 50 escritos solicitando una segunda corrección. Tras formalizar los escritos un compañero o compañera del departamento de la docente titular corrigió de nuevo los exámenes y determinó en todos los casos que bajo su criterio, corrigiendo un examen escrito, que la nota exacta puesta por la docente titular de la asignatura era la merecida.

Después de contarnos su experiencia personal nos vuelve a contestar a la pregunta: ¿Hay miedo por parte del estudiantado a presentar quejas en la Universidad? "Sí, y es normal que en ciertos casos haya miedo para reclamar. Los estudiantes se encuentran con el corporativismo". Y lanza una pregunta a las defensorías: "¿cómo combatimos el corporativismo en la Universidad?".

Esta situación es persistente en el tiempo, desde las defensorías universitarias se debería trabajar por romper la barrera del miedo y luchar porque sean realmente efectivas, así como visibilizarlas. 